\title{
Design and Operation of a MEMS Microengine Fabricated from Asymmetrical Polysilicon Surface Micromachined Electrothermal Microactuators
}

\author{
Alfred J. Jayachandran and Edward S. Kolesar* \\ Department of Engineering \\ Texas Christian University \\ Tucker Technology Center \\ TCU Box 298640 \\ 2840 Bowie Street, Fort Worth, TX 76129 USA \\ e-mail: e.kolesar@tcu.edu
}

*Faculty Research Mentor

\begin{abstract}
Several electrically-driven microactuators have been investigated for positioning individual elements in microelectromechanical systems (MEMS). The most common modes of actuation are electrostatic, magnetostatic, piezoelectric and thermal expansion. Unfortunately, the forces produced by electrostatic and magnetostatic actuators tend to be small, and to achieve large displacements, it is necessary to either apply a large voltage or operate the devices in a resonant mode. On the other hand, piezoelectric and thermal expansion actuators can be configured to produce large forces and large displacements. However, piezoelectric materials are not routinely supported by commercial MEMS foundries. These limitations have focused attention on thermally-actuated devices for generating the large forces and displacements required for a microengine. This research compares the performance of the single- and double-hot arm electrothermal actuator designs, and describes the practical implementation of a linear stepping microengine. The linear stepping microengine incorporates a shuttle whose bi-directional linear motion can be controlled by activating two independent sets of orthogonal mechanical elements. One of the mechanical elements is called the pawl, and when it is activated by the set of three parallel single-"hot" arm electrothermal actuators, it contacts the translator element. Activation of the set of eight double--"hot" arm electrothermal actuators causes the translator element to move, correspondingly causing the shuttle to change its position. Smooth continuous motion has been achieved by controlling the relative phase relationship between the set of independent square-wave voltage signals. When the relative phase relationship is maintained, microengines incorporating single- and double-"hot" arm electrothermal actuators have been continuously operated under ambient conditions using square-wave frequencies spanning $0.1 \mathrm{~Hz}$ to $100 \mathrm{kHz}$ for time periods exceeding 126 hours. The pawl and translator move in a sequential pattern, thus moving the shuttle. Inertial loads (in the form of a geared mechanical translation shuttle), whose masses were more than 100 times that of the entire microengine, have been translated. The concept for using a circular array of microengines that are coupled to mechanical shuttle and

Proceedings of the 2003 ASEE Gulf-Southwest Annual Conference

The University of Texas at Arlington

Copyright (C) 2003, American Society for Engineering Education
\end{abstract}


gripper elements will be addressed for the practical application of focusing a polymeric lens. The electrothermal actuator and microengine designs were accomplished with the MEMSPro ${ }^{\mathbb{B}}$ software program, and they were fabricated using the MEMSCAP, Inc. Multi-User Microelectromechanical Systems (MEMS) Process ${ }^{\circledR}$ (MUMPs) foundry at the Micro-electronics Center of North Carolina (MCNC).

\section{Introduction}

The seamless integration of conventional microelectronics with three-dimensional, microdynamic, mechanical components can readily be accomplished using microelectromechanical systems (MEMS) technology. Numerous electrically driven microactuators have been investigated for positioning individual elements in microelectromechanical systems (MEMS) with the most common modes of actuation being electrostatic, magnetostatic, piezoelectric and thermal expansion [1]. Electrostatic and Magnetostatic actuators produce relatively small forces, which are insufficient to achieve large displacements. In order to achieve large displacements due to larger forces, piezoelectric and thermal expansion actuators should be used. Unfortunately, piezoelectric materials are not routinely supported in the fabrication processes offered by commercial MEMS foundries, as a result, these limitations have focused attention on thermally actuated devices for generating large forces and displacements [2].

Since thermal actuation is the most viable option for microengines, this research focuses on harnessing the design and performance of the MEMS electrothermal microactuator for use in a linear and geared microengine [3]-[8]. As depicted in Fig. 1, the conventional MEMS polysilicon electrothermal microactuator uses Joule heating to generate thermal expansion and movement [8]. When current is passed through the actuator from anchor-to-anchor, the narrower arm, or "hot" arm, has a larger current density, due to its smaller cross-sectional area, which causes it to heat and expand along its length more than the "cold" arm. Since both arms are joined at their free (non-anchored) ends, the difference in length of the two arms causes the microactuator tip to move in an arc-like pattern about the flexure element incorporated at the anchor end of the "cold" arm. Removing the current from the device allows it to return to its equilibrium state, as long as the actuator remained in its elastic region. [9]

\section{Design and Fabrication}

The design of the two electrothermal microactuators was accomplished with the MEMSPro ${ }^{\circledR}$ (formerly L-Edit ${ }^{\circledR}$ ) CAD software program [10], and the devices were fabricated using the MEMSCAP, Inc. MUMPs foundry service [11]. The electrothermal actuator arms were fabricated using the $2 \mu \mathrm{m}$ thick releasable structural polysilicon layer, poly 1 (Fig. 1). The authors have previously reported that a practical "hot" arm width is $2 \mu \mathrm{m}$, and that a $62 \mu \mathrm{m}$ long flexure yielded excellent performance [9], so these parameters were not varied in this investigation. However, the width of the flexure was reduced in the double-"hot" arm microactuator variant, and changing the length of the "cold" arm systematically varied the lengths of the electrothermal microactuators.

Proceedings of the 2003 ASEE Gulf-Southwest Annual Conference

The University of Texas at Arlington

Copyright (C) 2003, American Society for Engineering Education 


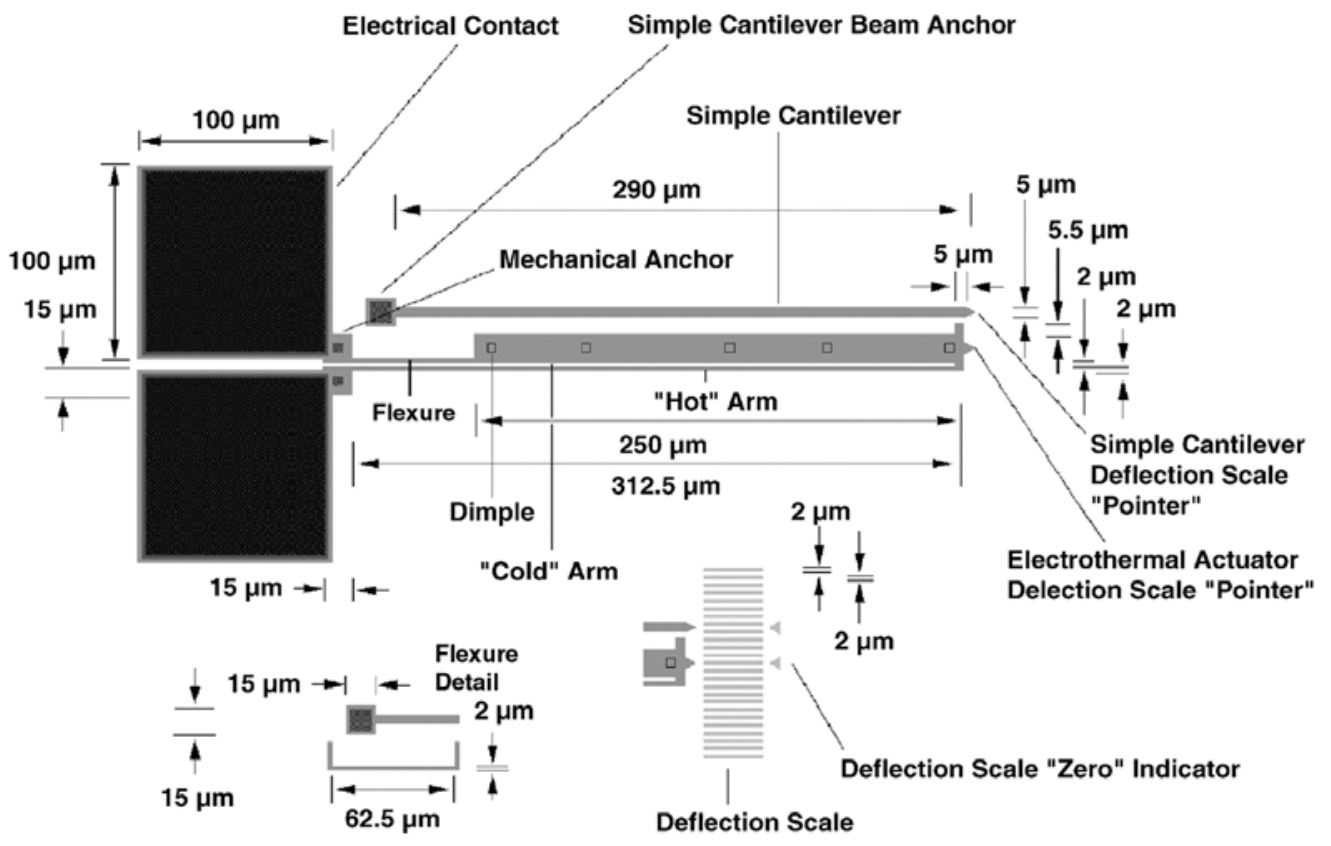

Figure 1. Conventional single-"hot" arm polysilicon electrothermal actuator design with an adjacent simple cantilever used to measure deflection force. The inset depicts a magnified view of the thermal beam's tip ("pointer" feature) and scale used to measure deflection.

Adjacent to the pair of mechanical anchors for the "hot" and "cold" arms in the single-"hot" arm microactuator, and the two "hot" arms in the double-"hot" arm device, are pairs of adjoining electrical contact pads composed of a stacked layer of poly 1, poly 2, and gold. The physical size of the contact pads (100 $\mu \mathrm{m}$ square) facilitates either making repetitive mechanical probe contacts (or implementing permanent wire bonds). The electrothermal actuator tip deflection scale and the equilibrium rest position triangular index marker (Figure 1) were rendered using the poly 0 structural layer. To minimize stiction problems that are commonly associated with the wet chemical sacrificial glass release etch process, the MUMPs carbon dioxide $\left(\mathrm{CO}_{2}\right)$ criticalpoint drying scheme was utilized [11].

To experimentally measure the force that can be generated at the tip of an activated electrothermal microactuator, a long and narrow simple cantilever was positioned parallel to the "cold" arm in each design (Figure 1). The end of the $5 \mu \mathrm{m}$ wide simple cantilevers closest to the electrical contact pads was anchored to the silicon nitride substrate. Two dimple structures (each $1 \mu \mathrm{m}$ square) were uniformly spaced along the simple cantilevers to minimize frictional losses from contact with the silicon nitride substrate during in-plane translation. The deflection marker positioned at the other end of the simple cantilever was incorporated along with a poly 0 deflection scale to measure the simple cantilever's in-plane translation when contacted by an activated electrothermal microactuator. The physical gap between the deflectable tips of the simple cantilever and the electrothermal microactuator's "cold" arm was $2 \mu \mathrm{m}$.

Proceedings of the 2003 ASEE Gulf-Southwest Annual Conference

The University of Texas at Arlington

Copyright (O) 2003, American Society for Engineering Education 


\section{Results}

The characteristics of the three microengine design variants were experimentally measured using a Karl Suss microprobe station (model PM 5; 2000 x magnification), a pair of Karl Suss RF microprobes (model PH 150), and the set of Pragmatic Instruments MEMS Driver System arbitrary waveform generators (model 2414A).

The microengines are based on the addition of electrothermal actuators in parallel in order to harness a greater force. When two sets of thermal actuators are used in conjunction, one to engage a pawl and another to move a linear mechanical slider, we can achieve continuous linear motion. The pawl is activated first, driving the translator down and forcing a mesh between the sets of gear teeth (Fig. 2 (B)). While the gear teeth sets are meshed, the translator is activated pushing the shuttle (Fig. 2 (C)). Before the translator finishes its cycle, the pawl is released so that the gear teeth sets are no longer meshed (Fig. 2 (D)). The translator is then released and returns to its original position (Fig. 2 (A)). By utilizing waveforms, created and applied using a set of Pragmatic arbitrary waveform generators, we can create continuous motion of the slider.
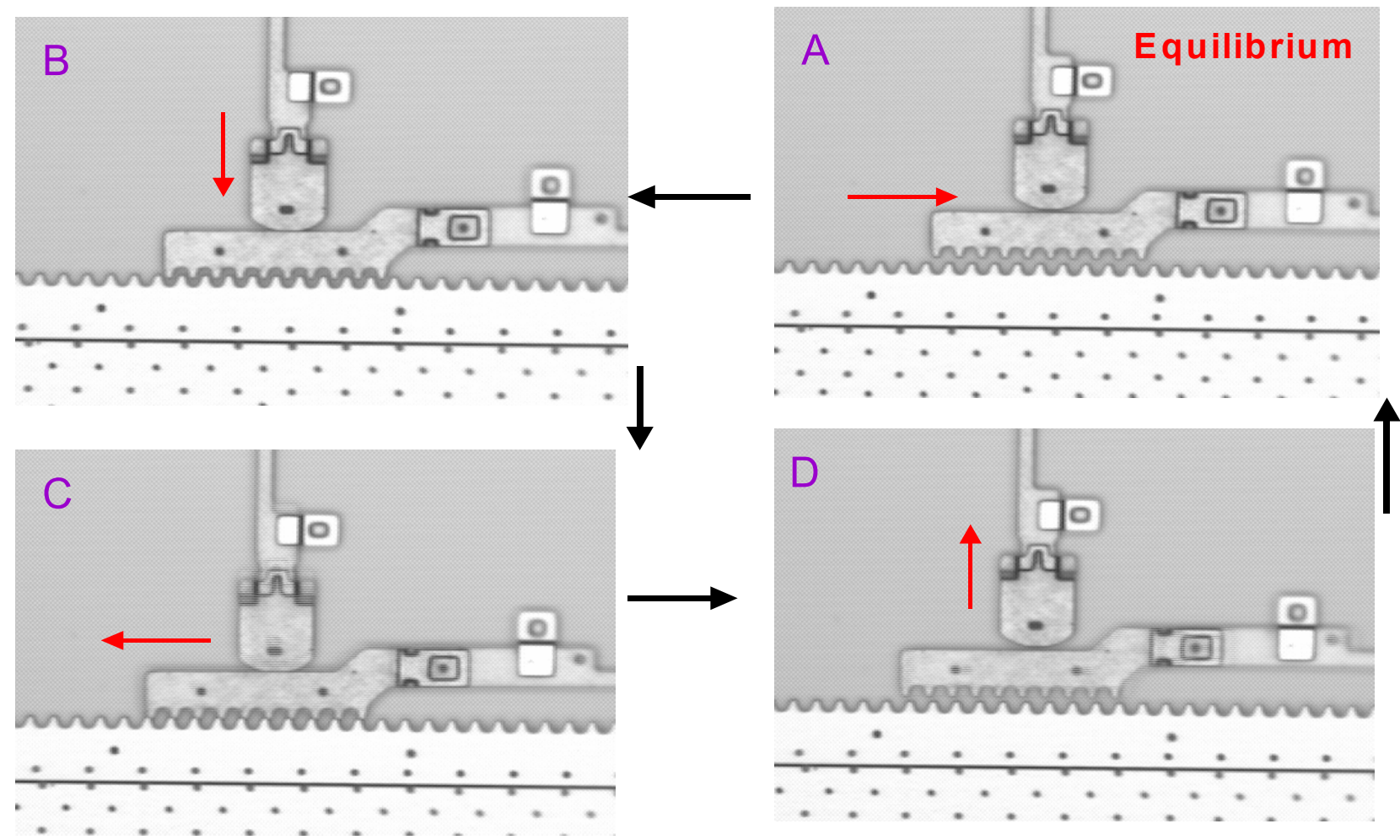

Figure 2. Microengine actuation cycle showing the movement paths of the translator and the pawl. The actuation cycle starts from the equilibrium position in frame (A), and then shows the pawl engagement (B), followed by the translator engagement (C). When the translator is near the end of its stroke, the pawl disengages (D), before the translator disengages, returning the system to the equilibrium state (A). 


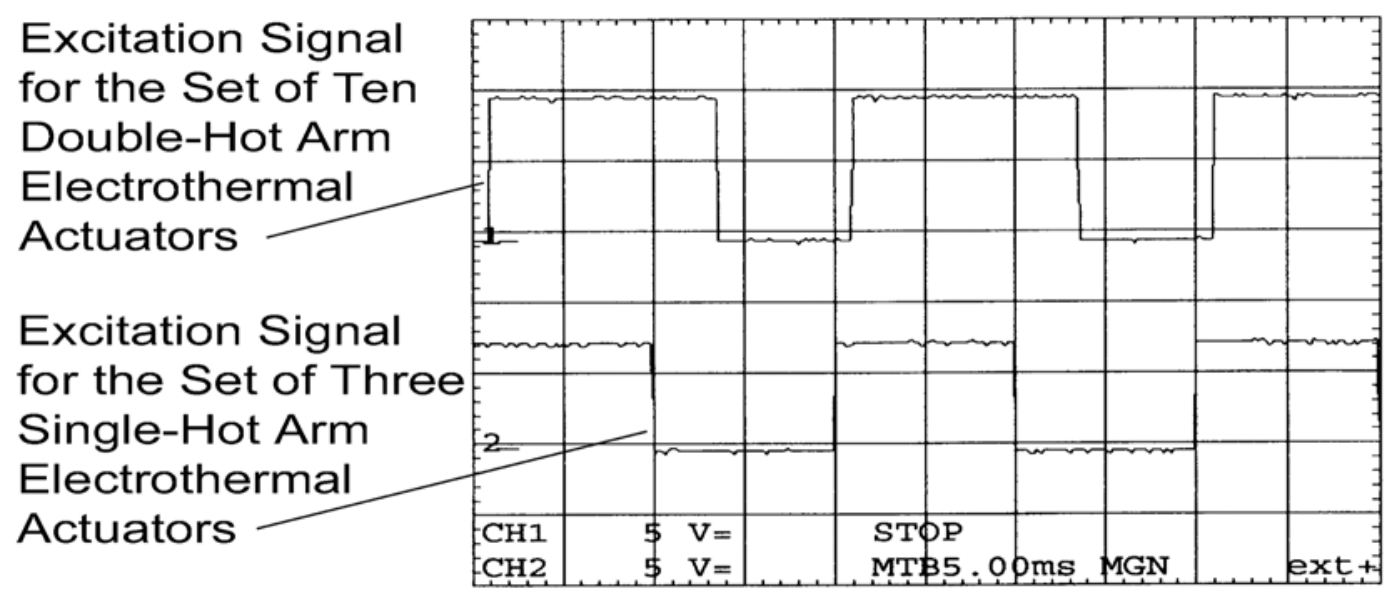

Figure 3. Excitation waveform for the electrothermally-actuated microengine showing typical voltage amplitudes and the relative phase relationship for the two interdependent excitation signals.

Currently we have created three microengine variants: 1) linear, 2) geared, 3) transmission. The linear microengine (Fig. 4) variant has the translator directly interface with the shuttle, opposed to the geared and transmission variants where the translator interfaces with the gear train in order to create slider motion. The linear microengine has been operated under ambient conditions using the square-wave frequencies spanning $0.1 \mathrm{~Hz}$ to $100 \mathrm{kHz}$, and have been continuously operated for time periods exceeding 126 hours.

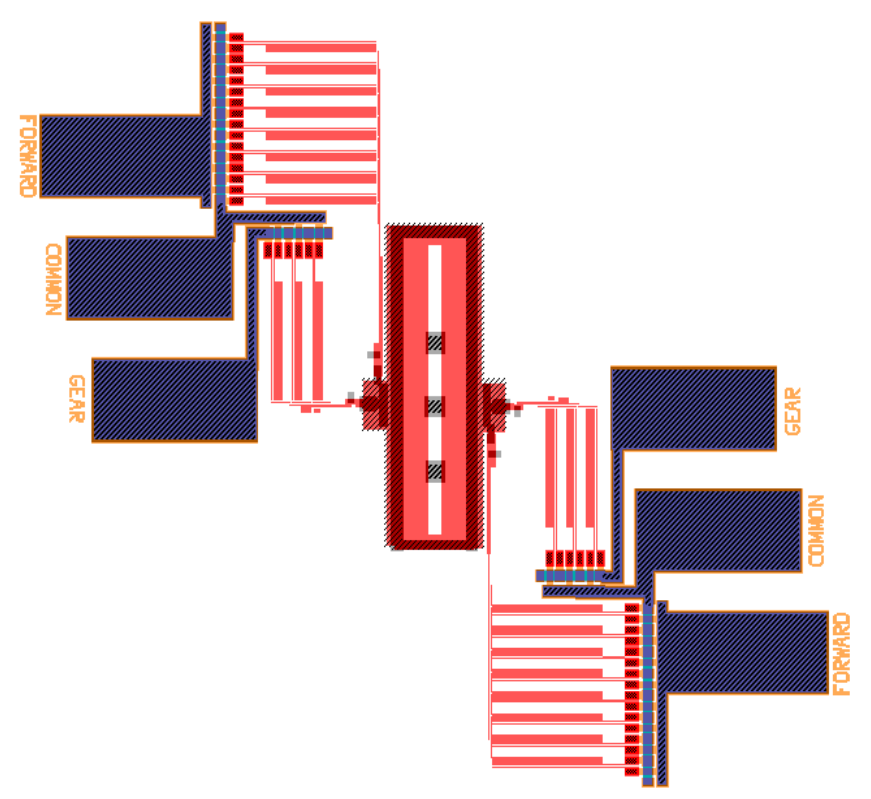

Figure 4. Linear Microengine - the eight single-"hot" arm electrothermal actuators control the motion of the mechanical translator, while the three parallel single-"hot" arm electrothermal elements control the pawl in order to achieve a circular pattern, achieving linear motion.

Proceedings of the 2003 ASEE Gulf-Southwest Annual Conference

The University of Texas at Arlington

Copyright (C) 2003, American Society for Engineering Education 
The geared microengine (Figure 5) uses two 100-micron gears coupled together. The translator interfaces with the first gear to convert linear motion into rotational motion. The first gear interfaces with the second gear, which will convert the rotational motion back into linear motion in order to move the shuttle. The transmission microengine variant (Fig. 6) utilizes a 50 micron first gear to rotate a 100 micron second gear. The different gear ratios allow us to have better control of the speed and power delivered to the shuttle.

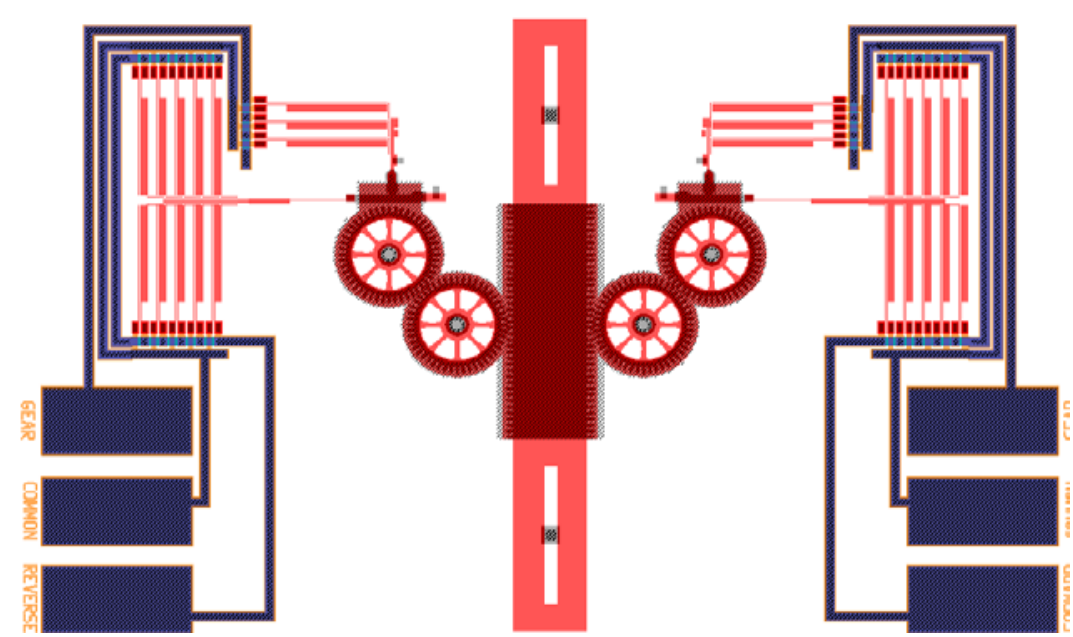

Figure 5. Geared Microengine - The geared linear translational element that contacts the two meshed gears is connected with a mechanical yoke to the array of ten single-"hot" arm electrothermal elements. When the array of three parallel single-"hot" arm electrothermal elements is activated, the pawl contacts the geared translator, forcing the translator's gear teeth to mesh with the circular gear. Rotational motion is achieved when the array of ten single"hot" arms is activated.

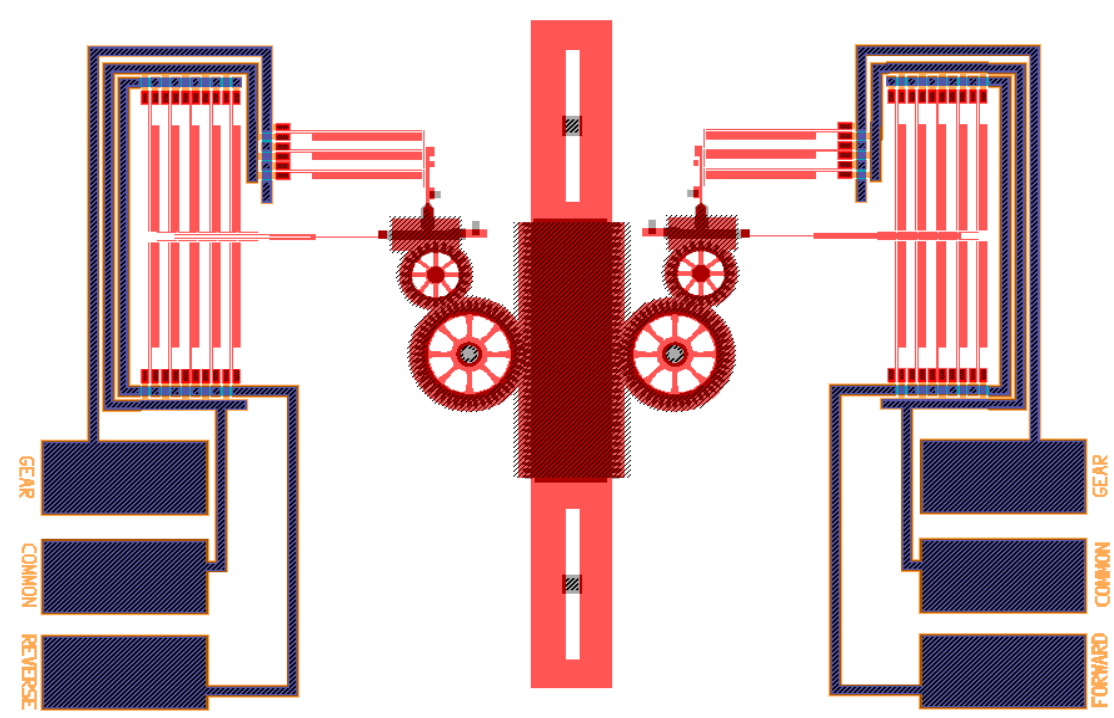

Figure 6. The Transmission Microengine operates similar to the geared microengine, but utilizes two different size gears in order to harness different power requirements.

Proceedings of the 2003 ASEE Gulf-Southwest Annual Conference

The University of Texas at Arlington

Copyright (C) 2003, American Society for Engineering Education 
Figure 7 shows the microengine depicted in Figure 6 in operation when the waveform depicted in Figure 3 was used.

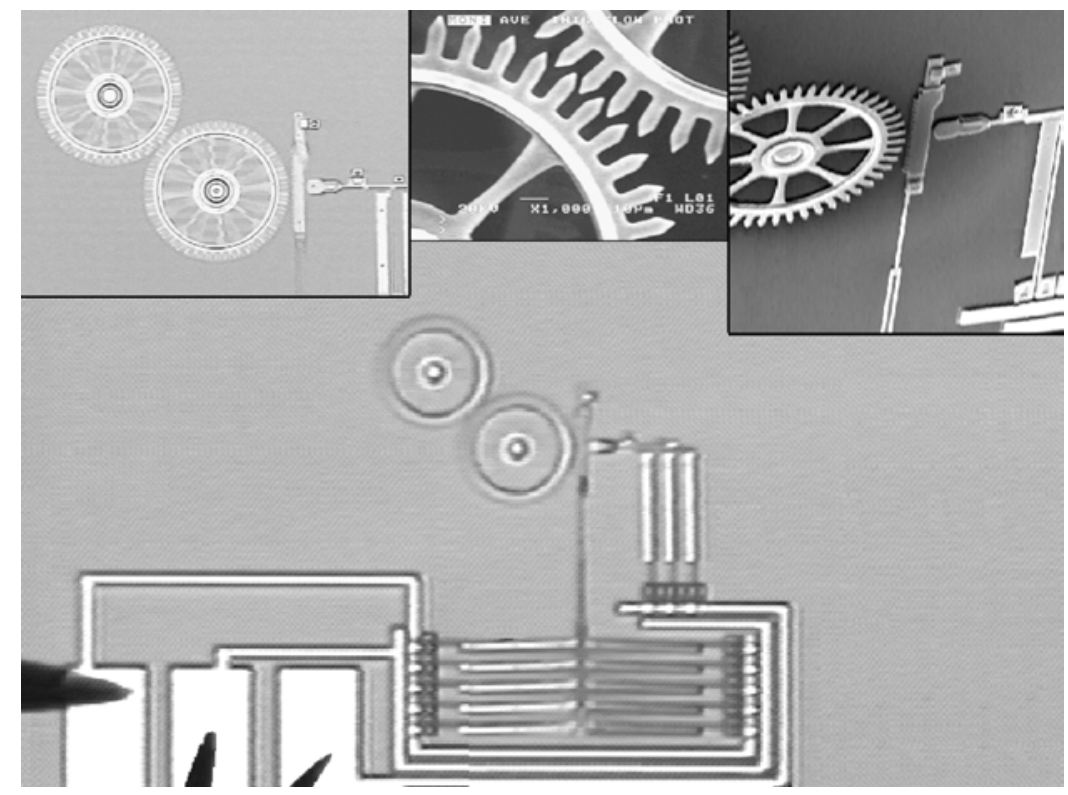

Figure 7. SEM micrograph of the electrothermal microengine with several high-magnification feature insets.

\section{Conclusion}

Single- and double-"hot" arm electrothermal microactuators capable of producing in-plane tip deflections spanning 1-10 $\mu \mathrm{m}$ and generating tip forces exceeding $8 \mu \mathrm{N}$ were designed and fabricated using the three-level polysilicon surface-micromachining foundry service that is available as the Multi-User Microelectromechanical Systems (MEMS) Process (MUMPS) through MEMSCAP, Inc. The electrothermal microactuators have been incorporated in electrothermal microengine variants, controlling the pawl and translator to achieve linear motion. The three microengine variants include the linear microengine, the simplest of the variants, the geared microengine, uses a gear train in order to convert rotational motion into linear movement, and the transmission microengine, that uses different sized gears to gain different speeds without changing the actuation levels and frequencies. The electrothermal microengine will be used as a bi-directional linear-stepper motor to function as a MEMS micro-positioning translator.

\section{References}

1. L. Ristic, Sensor Technology and Devices, Norwood, MA: Artech House, 1994.

2. C.S. Pan and W. Hsu, "An electro-thermally and laterally driven polysilicon microactuator," J. Micromech. Microeng., vol. 7, pp. 7-13, 1997.

3. H. Guckel, J. Klein, T. Cristenson, K. Skrobis, M. Laudon, and E.G. Lovell, "Thermo-magnetic metal flexure actuators," in Tech. Dig. Solid-State Sen. Act. Workshop, Hilton Head Island, SC, June 22-25, 1992, pp. 73-75.

Proceedings of the 2003 ASEE Gulf-Southwest Annual Conference

The University of Texas at Arlington

Copyright (C) 2003, American Society for Engineering Education 
4. J.H. Comtois and V.M. Bright, "Surface micromachined polysilicon thermal actuator arrays and applications," in Tech. Dig. Solid-State Sen. Act. Workshop, Hilton Head Island, SC, June 2-6, 1996, pp. 174176.

5. G.K. Fedder and R.T. Howe, "Thermal assembly of polysilicon microstructures," in Proc. IEEE Micro Electro Mechanical Systems Workshop, Nara, Japan, January 30 - February 2, 1991, pp. 63-68.

6. P.B. Allen, J.M. Wilken, and E.S. Kolesar, "Design, fabrication and performance evaluation of several electrical and mechanical silicon microstructures realized using the emerging technology of microelectromechanical systems (MEMS)," in Proc. 1997 ASEE Conf., Houston, TX, March 23-25, 1997, pp. 43-48.

7. D.N. Burns and V.M. Bright, "Design and performance of a double hot arm polysilicon thermal actuator," in Proc. SPIE, vol. 3224, October 1997, pp. 296-306.

8. E.S. Kolesar, P.B. Allen, J.T. Howard, and J.M. Wilken, "Thermally actuated microbeam for large in-plane mechanical deflections,” J. Vac. Sci. Technol. A, vol. 17, no. 4, July-August 1999, pp. 2257-2263.

9. W.E.Odom, and E.S.Kolesar, "Characterization of Symmetrical and Asymmetrical Polysilicon Surface Micromachined Electrothermal Actuators", Proceedings of the 2003 ASEE Gulf-Southwest Annual Conference, The University of Texas at Arlington, March 19, 2003.

10. MEMSPro ${ }^{\circledR}$ CAD Software Manual, MEMSCAP, Inc., Raleigh, NC 27609.

11. D. Koester, R. Mahedevan, A. Shishkoff, and K. Markus, Multi-User MEMS Processes (MUMPS) Introduction and Design Rules, revision 4, JDS Uniphase MEMS Technology Applications Center, 3021 Cornwallis Road, Research Triangle Park, NC 27709.

\section{Biographies}

Alfred J. Jayachandran

Alfred is a senior electrical engineering major at Texas Christian University where he works in the area of MEMS research under the guidance of Dr. Kolesar.

Edward S. Kolesar

Dr. Kolesar is currently a member of the faculty in the Department of Engineering at Texas Christian University, Fort Worth, TX, where he is the W. A. Moncrief Professor of Engineering. He has served as a technical consultant with The Johns Hopkins University, School of Hygiene and Public Health, Division of Environmental Health Engineering, Baltimore, Maryland; the USAF Scientific Advisory Board, Washington, D.C.; the ARDEX Corporation, Austin, Texas; the EG\&G Mound Applied Technologies Laboratory, Miamisburg, Ohio; SRI International, Menlo Park, CA; and the Lockheed Martin Corporation, Fort Worth, TX. He is a registered professional engineer; a member of Tau Beta Pi, Eta Kappa Nu, and Sigma Xi; and a senior member of the Institute of Electrical and Electronics Engineers. His current research interests include organic semiconductors, the development of integrated circuit microsensors, silicon micromachining techniques applied to laser absorbers, advanced multi-chip module packaging technologies, solid-state gas chromatography systems, and microelectromechanical systems (MEMS).

Proceedings of the 2003 ASEE Gulf-Southwest Annual Conference

The University of Texas at Arlington

Copyright (C) 2003, American Society for Engineering Education 